\title{
Impact of maintenance systems on the Hucul mares' reproductive rates
}

\author{
Jadwiga Topczewska' and Wanda Krupa \\ 'Department of Animals Production and Poultry Products Evaluation, Faculty of Biology and Agriculture, Rzeszow \\ University, Rzeszów, Poland, '2Department of Ethology and Technological Basis of Animal Production, Faculty of \\ Biological and Animal Breed, University of Life Sciences in Lublin, Lublin, Poland
}

\begin{abstract}
An assessment of the reproductive impacts of maintenance systems, stable-pasture keeping and natural pasture, on Hucul horses was undertaken during the period 1990-2010. During the period covered by the analysis, much higher reproductive results were obtained in natural breeding systems. During the same period (1990-2010), pregnancy levels of $82.2 \%$, fertility of $80.44 \%$, sterility of $17.76 \%$ including prolificacy of $77.45 \%$ were attained under guided breeding systems. The corresponding figures for natural breeding were $93.50 \%$, $90.25 \%, 6.50 \%$ and $85.56 \%$, respectively. On farm, where reproductive guided breeding system was practiced, the best breeding results were obtained by mating mares with stallions from Hroby line while the least were with stallions from Gurgul line. However, in stables where reproduction was devoid of human interference the Hroby and Goral lines were most benefitting. A decline in pregnancy and fecundity accompanied by an increase in sterility were observed on both breeding facilities.
\end{abstract}

Keywords: Hucul mares, coefficients of reproduction, trends, maintenance systems

\section{Introduction}

Hucul horses, a highland breed, command special attention in breeding and thus are the subject of numerous research studies (Gancarz \& Budzynski 2002, Georgescu et al. 2008, Kubacki et al. 2004, Komosa \& Purzyc 2009, Purzyc 2009). As a primitive breed, it is characterized by numerous important breeding traits such as longevity, resistance, high

Archiv Tierzucht 56 (2013) 24, 246-254

doi: 10.7482/0003-9438-56-024

Corresponding author:

Jadwiga Topczewska; email: j.topczewska@gmail.com

Department of Animals Production and Poultry Products Evaluation, Faculty of Biology and Agriculture Rzeszow University, Zelwerowicza 4, 35-601 Rzeszów, Poland
Received: 11 April 2012

Accepted: 8 January 2013

Online: 8 March 2013

() 2013 by the authors; licensee Leibniz Institute for Farm Animal Biology (FBN), Dummerstorf, Germany. This is an Open Access article distributed under the terms and conditions of the Creative Commons Attribution 3.0 License (http://creativecommons.org/licenses/by/3.0/). 
fecundity and endurance. This is like the Polish Konik horses which are protected under the Genetic Resources Protection Programme. The primary objective of the conservation programme is to increase the population to a safe minimum while preserving the racial genetic variability by fostering isolated lines and families.

In comparison to noble ones, primitive breeds are characterized by good reproductive indicators. This is often connected with natural ways of keeping. In the opinion of several researchers (Benhajali et al. 2010, Curry et al. 2007, Gorecka \& Jezierski 2002, McDonnell 2000), mares kept in family groups consisting of several females and a stallion intensely manifest symptoms of heat. The constant presence of a stallion in the herd, in turn, ensures mating at the optimum stage of ovulation. Keeping horses in herd system allows for the observation of sexual behaviour which do not occur when mares have contact with stallions only during mating. The reduced reproduction rates observed in many breeds may be due to ignorance of breeders concerning the behaviour of females in heat as well as improper maintenance conditions. It is doubtless that, in natural social groups consisting of several mares and a stallion, typical forms of behaviour for a particular phase of sexual cycle are decisively more prevalent (Crowell-Davis 2007).

The aim of this study was to evaluate the results of breeding Hucul mares in natural breeding as well as guided breeding systems during 1990-2010. Age and genealogical membership impact on the evaluated indicators were accounted for in the study.

\section{Material and methods}

The research material constituted of a herd of Hucul mares reared at the Experimental Institute of Zootechnics Station in Odrzechowa (facility A) and the Herd of Horse Stable in Polan (facility B) during 1990-2010. Both breeding programmes were realized under mountain weather conditions, most similar to conditions typical for the breed. In facility $A$, the animals were kept in a stable-pasture system. When oestrus was observed in mares during the breeding period, it was followed by a naturally controlled, in-hand, mating.

During the period of analysis, the number of mare mothers increased from 10 in 1990 to 35 in 2010 on hand, which offered the opportunity to examine a total of 532 mares per season. On the other hand, in facility B, the horses were kept under stable-free (pasture) conditions using the herd system all year round. In 1990, there was one herd, consisting of one stallion and four mares, which was steadily increased making two flock herds, each consisting of one stallion and 10 mares in 2001. The stallion remained with the mares all through the year in this site. The mating was devoid of human interference. A total of 286 mares per season were covered by the analysis in facility B.

Reproduction related information was obtained from breeding documentations. The following indicators were calculated: pregnancy rate being the ratio of pregnant mares to mated ones; fertility being the ratio of live births of foals to mares covered; sterility being the ratio of sterility in mares to mated ones; pregnancy loss classified into miscarriages and stillbirths; foal rearing indicators up to six months of age and prolificacy being the ratio of weaned foals to mares mated.

The breeding indicators for Hucul mares in both maintenance systems were compared with respect to their membership of female families, the line of stud stallions used for breeding, age of mares as well as the period 1990-2010. 
Using a mathematical function, linear trends that characterized the course of change in reproduction indicators during 1990-2010, were defined. The results were processed using the Statistica 9.0 package (StatSoft, Inc. Tulsa, OK, USA).

\section{Results}

The reproductive results for Hucul mares, taking into account their maintenance system, is presented in Figure 1. Clearly more favourable results of pregnancy, fertility and sterility were attained in natural maintenance when compared with the guided breeding system. The results were statistically significant. A slightly lower indicator for weaned foals was obtained under pasture maintenance. More fillies were given birth to in both sites during 1990-2010. The prolificacy indicator, a measure for productivity in stables, was between $77.45 \%$ for facility $A$ and $85.56 \%$ for facility $B$ (Figure 1).

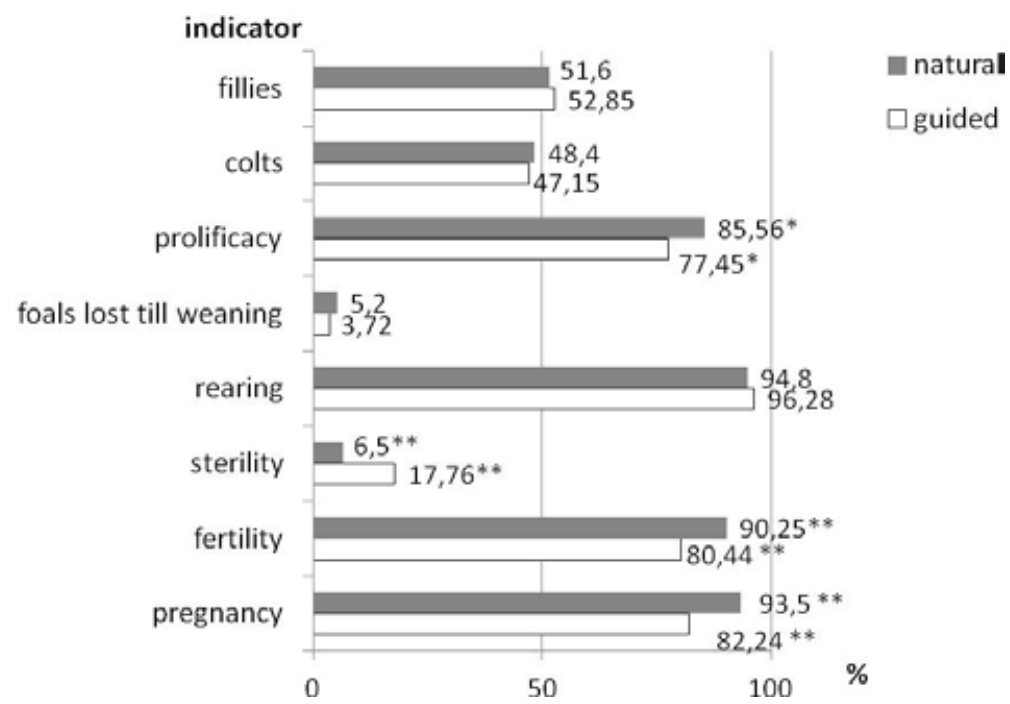

Figure 1

Reproductive indicators of Hucul mares from two breeding systems, ${ }^{*} P \leq 0.05, \quad{ }^{*} P \leq 0.01$

The results for pregnancy, fertility, sterility as well as duration of reproduction performance with respect to their belonging to female families are presented in Table 1 . The analysis showed that in facility $A$ the population of mares consisted of 6 families, i.e. Wolga, Wyderka, Polanka, Laliszka, Gurgul and Czeremcha. Individuals, representing a total of 10 families (Laliszka, Góralka Nowosądecka, Czeremcha, Polanka, Wyderka, Sroczka, Nakoneczna, Wolga, Wrona and Reda), were kept in facility B. To assess the impact of maintenance systems on the reproductive performance of Hucul mares, the reproductive rates of three families, i.e. Wolga, Wyderka and Polanka, held in both systems were compared. Pregnancy rate for Hucul mares held under the management system ranged from $80.29 \%$ to $83.91 \%$ while for those in the natural breeding system it ranged from $92.31 \%$ to $100 \%$. On the other hand, fertility ranged from $78.10 \%$ to $82.76 \%$ and from $90.11 \%$ to $93.33 \%$, respectively. The significant impact of maintenance systems on pregnancy, fertility and sterility in Hucul mares from Polanka family 
was demonstrated $(P \leq 0.01)$ whilst its impact on pregnancy in mares from Wyderka family was a bit less pronounced $(P \leq 0.05)$ (Table 1$)$.

Table 1

Description of pregnancy, fertility and sterility rates in Hucul mares in two breeding systems

\begin{tabular}{llcccccc}
\hline $\begin{array}{l}\text { Breeding } \\
\text { system }\end{array}$ & Family & $\begin{array}{c}\text { No mares- } \\
\text { season }\end{array}$ & Mating no & $\begin{array}{c}\text { Indicators } \\
\text { Pregnancy, } \%\end{array}$ & Sterility, \% & Fertility, \% & Season \\
\hline Guided & Wołga & 91 & 87 & 83.91 & 16.09 & 82.76 & 5.69 \\
& Wyderka & 182 & 172 & $83.82^{\mathrm{a}}$ & 16.18 & 80.92 & 5.35 \\
& Polanka & 145 & 138 & $80.29^{\mathrm{B}}$ & $19.71^{\mathrm{A}}$ & $78.10^{\mathrm{A}}$ & 6.30 \\
\multirow{2}{*}{ Natural } & & & & & & & \\
& Wołga & 34 & 34 & 94.12 & 5.88 & 91.18 & 7.40 \\
& Wyderka & 15 & 15 & $100.0^{\mathrm{a}}$ & - & 93.33 & 5.33 \\
& Polanka & 93 & 91 & $92.31^{\mathrm{B}}$ & $7.69^{\mathrm{A}}$ & $90.11^{\mathrm{A}}$ & 8.91 \\
\hline
\end{tabular}

Average in the columns marked with the same capital letters differ at $P \leq 0.01$, small letters at $P \leq 0.05$.

The effects of rearing foals, relative sex of progenies as well as prolificacy with respect to female families on both sites are presented in Table 2 . High results of rearing foals were noted in both guided breeding systems. No declines in progeny were observed in Wyderki and Wolga (facility B) families. The lowest prolificacy was observed in the Wolga family (facility A). During the period under cover, the mares gave birth to female progenies. A higher number of colt given birth to was confirmed only in the families of Wolga (facility A) as well as Wyderki (facility B) (Table 2). The impact of maintenance systems on prolificacy was observed $(P=0.05)$ in Hucul mares from Wolga and Polanka family.

Table 2

Presentation of the results of rearing Hucul foals in two breeding systems

\begin{tabular}{llccccc}
\hline \multirow{2}{*}{ Breeding system } & \multicolumn{2}{c}{ Foals no } & \multicolumn{2}{c}{ Sex } \\
Fuided & Family & Rearing, \% & Lost till weaning, \% & Colts, \% & Fillies, \% & Prolificacy, \% \\
\cline { 4 - 7 } & Wołga & 93.06 & 6.94 & 59.72 & 40.28 & $77.01^{\mathrm{a}}$ \\
& Wyderka & 96.43 & 3.57 & 42.14 & 57.86 & 78.03 \\
\multirow{4}{*}{ Natural } & Polanka & 97.20 & 2.80 & 42.99 & 57.01 & $75.91^{\mathrm{b}}$ \\
& & & & & & \\
& Wołga & 100.0 & - & 45.16 & 54.84 & $91.18^{\mathrm{a}}$ \\
& Wyderka & 100.0 & - & 71.43 & 28.57 & 93.33 \\
& Polanka & 95.12 & 4.88 & 40.24 & 59.76 & $85.71^{\mathrm{b}}$ \\
\hline
\end{tabular}

Average in the columns marked with the same small letters differ at $P \leq 0.05$.

Stud horses, used for mating mares under the management system between 1990 and 2010, represented the lines of Ousor, Polan, Gurgul, Goral and Hroby while for mares held in the natural breeding system, they were from the Gurgul, Goral, Hroby and Pietrosu lines. Breeding rates for Hucul mares serviced with studs representing lines from both systems are summarized in Table 3 . The most favourable breeding rates were obtained when mating was done using studs from Hroby line in the natural breeding system. The lowest pregnancy rate 
was observed in mares from the management system mated with studs from Gurgul line. Significant differences in the rates of pregnancy, fecundity, sterility and prolificacy of mares mated with studs from Gurgul line were observed $(P \leq 0.01)$, whilst regarding pregnancy and sterility amongst mares mated with studs from Goral line significant differences were less pronounced $(P \leq 0.05)$.

Table 3

Reproductive indicators of Hucul mares in two breeding systems with regards to the line of stud horses

\begin{tabular}{|c|c|c|c|c|c|c|}
\hline \multirow[b]{2}{*}{ Indicators } & \multicolumn{2}{|c|}{ Gurgul } & \multicolumn{2}{|c|}{ Goral } & \multicolumn{2}{|c|}{ Hroby } \\
\hline & Guided & Natural & Guided & Natural & Guided & Natural \\
\hline No. mares mating & 82 & 160 & 119 & 46 & 188 & 5 \\
\hline Pregnancy, \% & $78.05^{\mathrm{A}}$ & $92.50^{\mathrm{A}}$ & $81.51^{\mathrm{a}}$ & $93.48^{\mathrm{a}}$ & 84.57 & 100.0 \\
\hline Fertility, \% & $75.61^{A}$ & $90.0^{A}$ & 78.15 & 89.13 & 83.51 & 100.0 \\
\hline Sterility, $\%$ & $21.95^{\mathrm{A}}$ & $7.50^{\mathrm{A}}$ & $18.49^{a}$ & $6.52^{\mathrm{a}}$ & 15.43 & - \\
\hline \multicolumn{7}{|l|}{ Foals no. } \\
\hline Rearing \% & 91.94 & 92.57 & 100.0 & 100.0 & 95.54 & 100.0 \\
\hline Lost till weaning, $\%$ & 8.06 & 4.73 & - & - & 4.46 & - \\
\hline \multicolumn{7}{|l|}{ Pregnancy loss } \\
\hline Miscarriages, $\%$ & 1.56 & 2.03 & 3.09 & 4.65 & 0.63 & - \\
\hline Stillborn, \% & 1.56 & 0.68 & 1.03 & - & 0.63 & - \\
\hline Prolificacy, \% & $69.51^{A}$ & $85.63^{A}$ & 78.15 & 89.13 & 79.79 & 100.0 \\
\hline \multicolumn{7}{|l|}{ Sex } \\
\hline Colts, $\%$ & 46.77 & 47.92 & 47.31 & 58.54 & 45.86 & 60.0 \\
\hline Fillies, \% & 53.23 & 52.08 & 52.69 & 41.46 & 54.14 & 40.0 \\
\hline
\end{tabular}

Average in rows marked with the same capital letters differ at $P \leq 0.01$; small letters at $P \leq 0.05$.

The correlation coefficient for pregnancy, fecundity and sterility during 1990-2010 including its tendencies are summarized in Table 4. While a downward tendency was observed with respect to pregnancy and fecundity in both objects over the period covered by the study, the tendency regarding sterility was positive although these changes were very low in the natural maintenance system. The maintenance system had significant impact on the reproductive rates of Hucul mares $(P \leq 0.01)$.

Table 4

Tendencies in reproductive indicators both in natural (grazing) and in guided breeding systems during 1990-2010

\begin{tabular}{lccc}
\hline Indicators & \multicolumn{1}{c}{ Trend } & $\mathrm{R}^{2}$ & $\mathrm{r}_{\mathrm{xy}}$ \\
\hline Guided & & & \\
Pregnancy & $\mathrm{y}=89.1847-0.5452 \mathrm{x}$ & 0.1052 & $-0.3243^{* *}$ \\
Sterility & $\mathrm{y}=10.7758+0.5418 \mathrm{x}$ & 0.1032 & $0.3212^{*}$ \\
Fertility & $\mathrm{y}=87.6722-0.5702 \mathrm{x}$ & 0.1003 & $-0.3166^{* *}$ \\
Natural & & & \\
Pregnancy & $\mathrm{y}=93.6844-0.0271 \mathrm{x}$ & 0.0004 & $-0.0212^{* *}$ \\
Sterility & $\mathrm{y}=6.3156+0.0271 \mathrm{x}$ & 0.0004 & 0.0212 \\
Fertility & $\mathrm{y}=92.5031-0.1651 \mathrm{x}$ & 0.0133 & $-0.1152^{* *}$ \\
\hline
\end{tabular}

${ }^{*} P \leq 0.05,{ }^{*} P \leq 0.01$ 
Pregnancy and fertility indicators taking into account the mares' age are summarized in Figure 2 and in Figure 3. A clearly depressed reproductive performance was observed in females aged 14-15 and 18-19 kept in the guided breeding system. Similarly, depressed reproduction performance was noted among females aged 14-17 held in the herd system of pasture breeding. It was observed that the maintenance system had an impact on the pregnancy and fertility of Hucul mares aged $4(P \leq 0.01)$ and on the pregnancy of mares aged 6,18 and $19(P \leq 0.05)$.

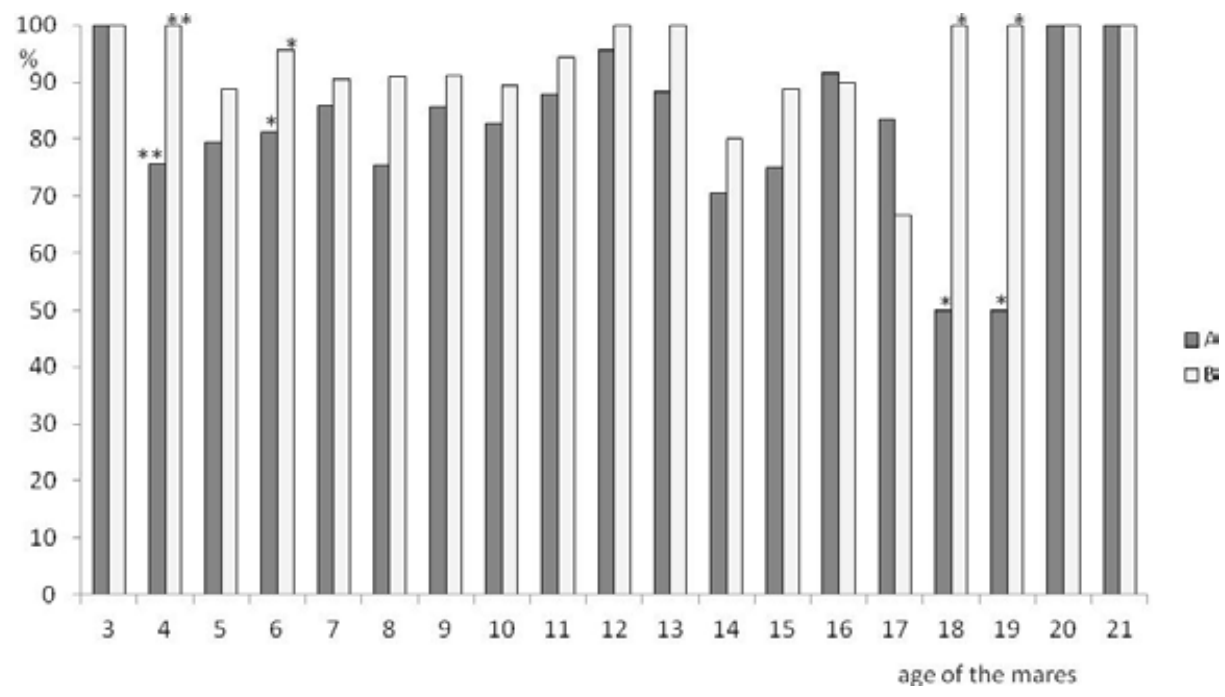

Figure 2

Pregnancy indicators of Hucul mares in two breeding systems, ${ }^{*} P \leq 0.05 ;{ }^{* *} P \leq 0.01$

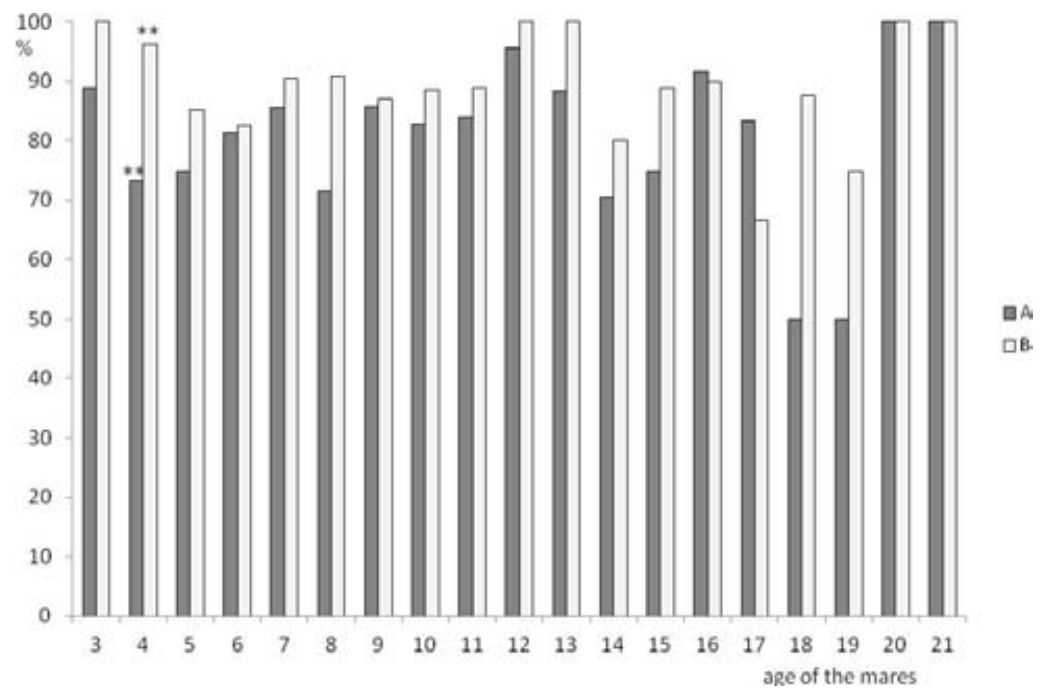

Figure 3

Fertility indicators of Hucul mares in two breeding systems, ${ }^{* *} P \leq 0.01$ 
The results for rates of pregnancy and fertility during 1990 and 2010 are summarized in Figure 3 and in Figure 4. Similar periods of distinctive decline in the analysed indicators were also observed. These periods in the guided breeding system (A), i.e. 1993, 1998, 2003 and 20072009 are presented in Figures 4 and 5 while those in the natural system (B), i.e. 1991, 1993, 2000, 2006 and 2009 are summarized in Figure 5. Significant differences in the pregnancy and fertility rates amongst Hucul mares kept in both, management and natural system, between 2007 and 2009 have been demonstrated $(P \leq 0.05)$.

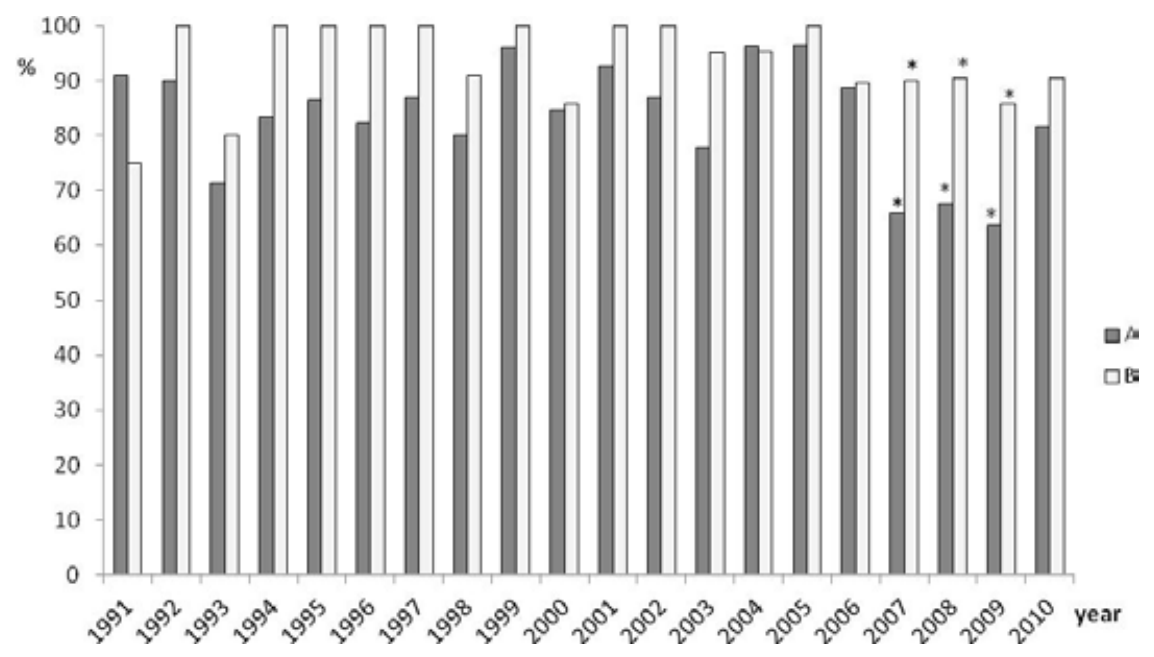

Figure 4

Pregnancy indicators of Hucul mares in two breeding systems, ${ }^{*} P \leq 0.05$

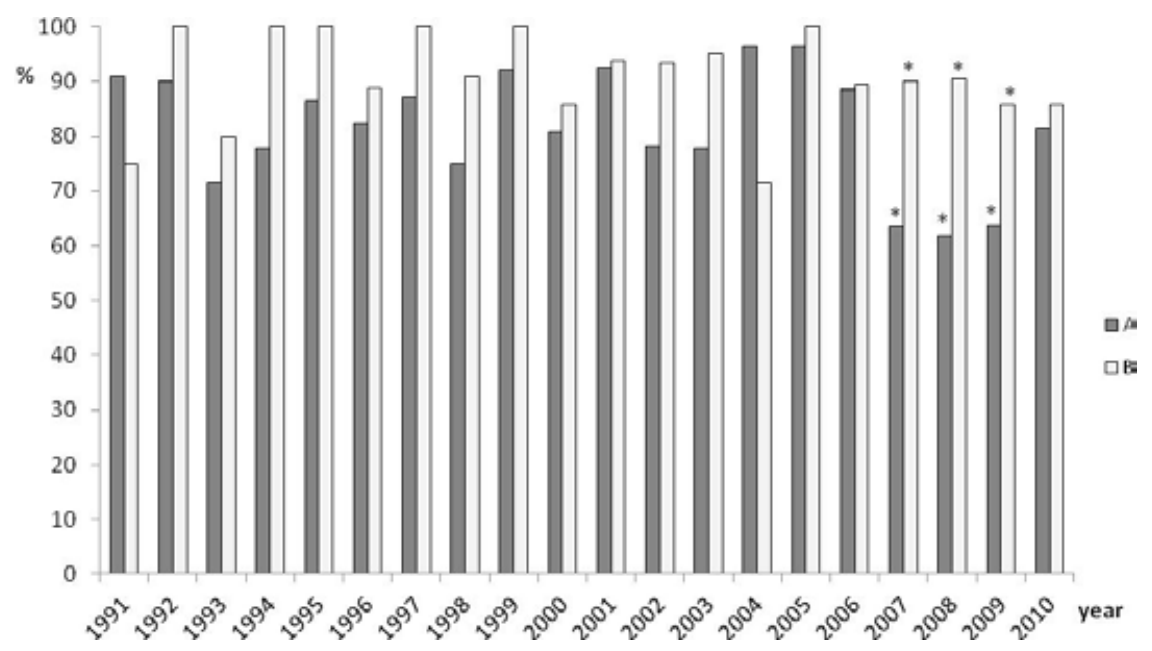

Figure 5

Fertility indicators of Hucul mares in two breeding systems, ${ }^{*} P \leq 0.05$ 


\section{Discussion}

Hucul horses are classified as primitive races, with a marked herd instinct and group hierarchy. They are characterized by longevity, resistance to harsh living conditions and nutrient deficiency as well as low demands but above all by a high fertility rate, which is extremely important from the breeders' point of view (Georgescu et al. 2008, Kubacki et al. 2004, Purzyc 2009). Moreover, lactational anoestrus does not occur as a physiological state in females of this species, which permits regular pregnancy (Deichsel \& Aurich 2005, Kosiniak-Kamysz \& Okolski 2007). Analysing breeding indicators for primitive races Balinska et al. (2007) demonstrated that the Polish Konik mares from SK Dobrzyniewo yielded 86.9\% pregnancy and $11.9 \%$ sterility on average for the period between 1980 and 2003. These results were somewhat better than those obtained in our study for facility $A$ but lower than in facility B. While analysing the reproductive performance of mares of the Polish Konik reared in the Dobrzyniewo stud farm, Kubacki et al. (2010) showed that there exists a positive steady increase in basic reproduction indicators. While the analysed population of Hucul mares showed negative tendencies in pregnancy and fertility rates, those for sterility showed a positive trend. This phenomenon should be regarded as strongly unfavourable in breeding.

Analysing results of reproduction performance in Hucul mares kept in Gladyszow stud farm during 1993-2003, Kubacki et al. (2004) obtained a marked growth tendency in basic indicators. Gancarz et al. (2002) compared the breeding indicators for Hucul mares kept in Bieszczady using the herd and stabling system and demonstrated visibly higher values for those kept in flock system.

A significant difference in fertility in favour of pasture keeping was confirmed by Davies Morel \& Gunnarsson (2000) in Iceland's mares and stallions. Such systems, being similar to the natural living conditions for primitive horse races, encourage the attainment of higher fertility.

The evaluation of the performance value is an essential element in horse breeding. Much of the reared Huculs are used sport-wise and its start often coincides with the breeding season. Sairanen et al. (2011) postulates that genetic improvement of racing qualities ought not lead to reduced fertility. Davies Morel \& Gunnarsson (2000) further state that breeding stallions engaged in intensified training achieved higher fecundity than those trained lightly or not trained at all. According to the authors, this has been achieved through the successive culling of individuals with reduced fertility.

Davies Morel \& Gunnarsson (2000) also emphasis that there exists a slightly significant decline in fertility with age, which was also observed in mares of primitive races in our studies. Mares older than 20 years giving birth to and weaning offspring are reared in the two facilities covered by the study.

According to McDonnell (2000), simple changes in the management of herds of horses could improve their reproductive and fertility efficiency. In a guided breeding system, the mares and stallions often only come in contact during mating which can substantially disrupt appropriate sexual reaction. Curry et al. (2007) emphasize that keeping horses in a traditional stable system limits the full expression of sexual behaviour and may lead to the misinterpretation of a species-typical behaviour. Similar to social types, types of sexual behaviour are regulated by a number of complementary elements which are strongly influenced by living conditions. 
In conclusion, it needs to be emphasized that distinctively improved values of breeding indicators were observed in Hucul horses kept in the pasture (grazing) herd system. A drop in reproduction results were observed in mares between 14 and 16 years of age irrespective of the breeding conditions. The fact that a negative tendency with respect to fertility and pregnancy indicators was observed in both systems during the period under cover also seems to be disturbing. This was specifically evident in the guided breeding system.

A favourable practice is the keeping of a herd of Hucul horses using the natural system. This allows for the exposure of race typical breeding potentials. Such a herd may serve as gene reserves whenever reproduction problems appear in horse breeding. Therefore it seems appropriate to consider it mandatory to keep part of the herd of Hucul horses in natural grazing system.

\section{References}

Balinska K, Iwanczyk K, Wolc A (2007) [The evaluation of reproduction and productivity indices in Polish Konik female lines from the Stud Farm Dobrzyniewo.] Rocz Nauk PTZ 3, 65-78 [in Polish]

Benhajali H, Richard-Yris MA, Ezzaouia M, Charfi F, Hausberger M (2010) Reproductive status and stereotypies in breeding mares: A brief report. Appl Anim Behav Sci 128, 64-68

Crowell-Davis SL (2007) Sexual behavior of mares. Horm Behav 52, 12-17

Curry MR, Eady PE, Mills DS (2007) Reflections on mare behavior: Social and sexual perspectives. J Vet Behav Clin Appl Res 2, 149-157

Davies Morel MCG, Gunnarsson V (2000) A survey of the fertility of Icelandic stallions. Anim Reprod Sci 64, 49-64

Deichsel K, Aurich J (2005) Lactation and lactational effects on metabolism and reproduction in the horse mare. Livest Prod Sci 98, 25-30

Gancarz J, Budzynski M, Budzynska M (2002) [Reproductive indices in Hucul mares with respect to the breeding system.] Ann UMCS, Sectio EE, Vol. XX, 229-233 [in Polish]

Georgescu SE, Manea MA, Costache M (2008) The genetic structure of indigenous Romanian Hucul horse breed inferred from microsatellite data. Roum Biotechnol Lett 13, 4030-4036

Gorecka A, Jezierski T (2002) [Social and sexual behavior of horses under semi-natural and stable conditions in relation to their reproductive efficiency - a review.] Pr Mater Zoot 60, 15-25 [in Polish]

Komosa M, Purzyc H (2009) Konik and Hucul horses: A comparative study of exterior measurements. J Anim Sci 87, 2245-2254

Kosiniak-Kamysz K, Okólski A (2007) [Recent scientific and practical achievements in horse reproduction.] Postępy Nauk Rolniczych 3, 43-64 [in Polish]

Kubacki S, Kario W, Kubacki P, Grygiel A (2004) [The analysis of breeding performance of Hucul breed of horses in SK Gładyszów in years 1993-2003.] Zesz Nauk Przegl Hod 72, 211-217 [in Polish]

Kubacki S, Pikulik F, Mrozik-Gliszczynska E, Swiecicka N (2010) The results of reproduction utility of the Polish primitive horse in the chosen stud farm in Poland in the period. J Centr Europ Agricul 11, 159-164

McDonnell SM (2000) Reproductive behavior of stallions and mares: comparison of free-running and domestic in-hand breeding. Anim Reprod Sci 60-61, 211-219

Purzyc $\mathrm{H}$ (2009) Focus on Hucul horses during postanatal development in view of chosen morphometric traits. Rev Med Vet (Toulouse) 160, 500-506

Sairanen J, Katila T, Virtala A-M, Ojala M (2011) Effects of racing on equine fertility. Anim Reprod Sci 124, 73-84 